\title{
AS LEGISLAÇÕES EDUCACIONAIS QUE FUNDAMENTAM O USO DE TECNOLOGIAS DIGITAIS PARA O ENSINO NO BRASIL: UM OLHAR SOBRE OS DIAS ATUAIS
}

The Educational Legislations Supporting the Use of Digital Technologies for Teaching in Brazil: a Look at the Current Days

\author{
João Ferreira Sobrinho Junior ${ }^{1}$ \\ Cristina de Cássia Pereira Moraes ${ }^{2}$
}

\begin{abstract}
Resumo: Esta pesquisa se propôs a identificar as legislações que fundamentam o uso de tecnologias digitais para o ensino no Brasil hodiernamente. Para responder a tal cenário, dispôs-se de pesquisa documental e bibliográfica a partir de trabalhos científicos e documentos oficiais para o levantamento, coleta e análise dos dados de forma qualitativa. E, como resultado da pesquisa, identificamos e destacamos três legislações hodiernas que estabelecem orientações para o uso de tecnologias digitais, as quais são: Decreto $\mathrm{n}^{\circ} 9.057$, de 25 de maio de 2017: Regulamenta o art. 80 da Lei $n^{\circ}$ 9.394, de 20 de dezembro de 1996 que estabelece as diretrizes e bases da educação nacional; Resolução $n^{\circ} 3$, de 21 de novembro de 2018 que atualiza as Diretrizes Curriculares Nacionais para o Ensino Médio; e, por fim, o Parecer CNE/CP No: 5/2020 (retificado pelo $\mathrm{N}^{\mathrm{o}}$ : 9/2020 e homologado dia 09.07.2020 no Diário Oficial da União) que reorganiza o calendário escolar e da possibilidade de cômputo de atividades não presenciais para fins de cumprimento da carga horária mínima anual, em razão da Pandemia da COVID-19. Conclui-se que a legislação educacional acompanha os tempos, com isso, em períodos cada vez menores, esta haverá de se adequar frente aos avanços das tecnologias digitais que se postam em nossos dias. Logo, a legislação é ponto crucial e assim deve e será utilizada à normatização e implementação das ações delineadas pelos entes e atores educacionais.
\end{abstract}

Palavras-chave: Legislação do Ensino. Aprendizagem Híbrida. Tecnologia Educacional.

\begin{abstract}
This research aimed to identify the laws that support the use of digital technologies for teaching in Brazil today. In order to respond to this scenario, a documental and bibliographic research was used, based on scientific papers and official documents, for the survey, data collection, and data analysis in a qualitative way. As a result of the research, we identified and highlighted three modern legislations that establish guidelines for the use of digital technologies: Decree No. 9.057, of May 25, 2017: Regulates the art. 80 of Law No. 9.394, of December 20, 1996 that establishes the guidelines and bases of national education;

\footnotetext{
${ }^{1}$ Licenciatura Plena em Pedagogia (2004) e Bacharelado em Sistemas de Informação pela Universidade Federal do Acre (2009), Mestrado em Ciência da Computação pela Universidade Federal de Pernambuco, Doutorando em História pela Universidade Federal de Goiás. ORCID ID: https://orcid.org/0000-0003-3756-9797. E-mail: joffersoju07@hotmail.com.

2 Graduação em Licenciatura em História pela Faculdade de Ciências Humana e Filosofia de Araguari (1985), Mestrado em História pela Universidade Federal de Goiás (1995), Doutorado em História das Ideias pela Universidade Nova de Lisboa (2005), Professora Associada da Universidade Federal de Goiás. ORCID ID: https://orcid.org/0000-0001-8767-7070.E-mail: cristinadecassiapmoraes@gmail.com
} 
Resolution No. 3, of November 21, 2018 that updates the National Curriculum Guidelines for High School; and finally, the CNE/CP Opinion No.: 5/2020 (rectified by No.: 9/2020 and homologated on 09. 07.07.2020 in the Diário Oficial da União) which reorganizes the school calendar and the possibility of counting non presential activities for the purpose of fulfilling the minimum annual workload, due to the COVID-19 Pandemic. This research concluded that the educational legislation keeps up with the times, and that, in shorter and shorter periods of time, it will have to adapt to the advances in digital technologies that are taking place nowadays. Therefore, legislation is crucial. It should and will be used to regulate and implement the actions outlined by the educational entities and players.

Keywords: Teaching Legislation. Hybrid Learning. Educational Technology.

\section{Introdução}

O modelo de ensino com a utilização de tecnologias digitais, implementado em tempos de pandemia, foi a "toque de caixa", pois as redes de ensino não tiveram tempo e nem recursos para o planejamento pedagógico, metodológico, para estabelecerem conexão entre a prática e o currículo, ou seja, para fazer uma discussão mais aprofundada e fundamentada. $\mathrm{O}$ processo histórico da implementação das tecnologias digitais no ensino básico no Brasil teve sua duração abreviada, pois o que seria feito em cinco ou dez anos foi confinado em apenas um ou dois meses por conta da COVID-19, dessa forma, transformando esse contexto em uma tarefa árdua e nem sempre precisa ou satisfatória para o aprendizado dos alunos.

Um ponto a ser deixado claro é que não há dicotomia entre o uso da tecnologia digital e o ensino presencial, sendo assim, devem ser promovidas formas de conciliá-los através de um diálogo pedagógico para que se aproveite o melhor dos dois modelos. Isso sem esquecer das dificuldades socioeconômicas de milhões em nosso país, pois a responsabilidade dos governos é de suprir o bem-estar da população e, assim, inclúi-los dentro das políticas educacionais governamentais, para que isso promova sua inclusão social e, nesse caso, a inclusão digital. Esse diálogo deve ser estabelecido entre todos os atores educacionais do país com a finalidade de se alcançar o objetivo da educação na escola pública que é atingir a qualidade do ensino para todos.

Assim sendo, nesses tempos de pandemia no Brasil, os modelos e a organização da educação estão sendo testados e as dúvidas sobre como será a comunicação entre a escola e os alunos pós-pandemia são notórias e, assim, através das lives, acentuam-se os debates de especialistas de norte a sul do país sobre esse futuro próximo. Essas dúvidas não se resumem simplesmente às formas como serão reorganizadas as escolas, mas se percebe que mudanças certamente virão na forma da comunicação entre a escola e o aluno no ensino público e, destarte, a tecnologia digital é um dos atores principais dessa mudança. Sob esse cenário intrigante nos questionamos: Quais as legislações que fundamentam o uso de tecnologias digitais para o ensino no Brasil nos dias de hoje?

A metodologia é baseada em uma abordagem qualitativa sob o viés documental e bibliográfico. Sabe-se que esses dois tipos de pesquisas são semelhantes, no entanto, estas se diferem pela natureza de suas fontes, pois a pesquisa bibliográfica se fundamenta nas contribuições que provém de autores especialistas em determinada área através de trabalhos revisados, enquanto a documental é baseada em material que não foi analiticamente tratado e, assim, pode ser adequado interpretativamente ao objeto da pesquisa (GIL, 2002). No que tange à coleta, análise e discussão dos dados, primeiramente fizemos uma pesquisa inicial 
com fins de identificar os conceitos básicos relativos à aprendizagem híbrida para inserirmos a questão do uso das tecnologias digitais enquanto parte desse cenário. E, por fim, elencamos as principais legislações que permitem o uso dessas tecnologias digitais para ensino no Brasil hodierno com o propósito de se alcançar o objetivo desta pesquisa.

O objetivo deste artigo é identificar as legislações que fundamentam o uso de tecnologias digitais para o ensino no Brasil hodiernamente. Este trabalho é relevante, pois apresenta os marcos legais que permitem aprendizagem híbrida através da utilização das tecnologias digitais no país, visto que é notório que de um modo ou de outro a tecnologia digital tende a estar cada dia mais presente no ensino público, complementarmente a este. $\mathrm{E}$ assim, por si só, tal fato já justifica a pesquisa sobre essa temática.

\section{Aprendizagem híbrida: o uso de tecnologias digitais para o ensino}

O ensino nos dias de hoje é impactado pelas tecnologias que se apresentam à sociedade e, assim é, em maior ou menor grau influenciado por elas (DORIGONI; SILVA, 2007). Dessa forma, o ensino, no decorrer do tempo, transformou-se acompanhando as evoluções tecnológicas no qual estava imerso determinada sociedade. Desse modo, a comunicação pautada basicamente na oralidade dos tempos antigos foi aos poucos complementada pela escrita manual e impressa e, por fim, pelo uso dos recursos digitais a partir do advento da internet e o avanço tecnológico. As formas de se transmitir o conhecimento também seguiram esse caminho evolutivo, primeiramente com o ensino através da oralidade em pequenos grupos sociais, passando pelo uso dos recursos escritos. A partir do século XV, com a invenção da imprensa, os impressos passaram a ter presença por meio do modelo gutenberguiano e, por fim, culminando com a era digital na qual nos encontramos. Muito embora as tecnologias avancem, estas não levam necessariamente ao desaparecimento das anteriores, pois vão se "espremendo entre as outras e encontrando seus direitos de existência ao provocar uma refuncionalização nos papéis das anteriores" (SANTAELLA, 2013, p. 26).

Contemporaneamente, com o advento das ferramentas tecnológicas digitais vinculadas à internet, possuímos bens que se moldaram aos novos tempos como o telefone celular, que hoje é um minicomputador a partir do conceito de smartphone. Nesse cenário, o ensino não se pôs alheio como também foi influenciado por tal, trazendo modos díspares de se transmitir o conhecimento em relação ao que já se tinha e, nesse sentido, citamos a aprendizagem híbrida.

A aprendizagem híbrida ou ensino híbrido, do inglês blended learning ou b-learning, vem ocupar um espaço no qual a educação dita tradicional - pautada na transmissão unilateral e meramente expositiva do conhecimento - não estava conseguindo suprir contemporaneamente. Tal afirmação vem corroborada por Tapscott e Williams (2010) ao afirmarem que a aprendizagem deixa de fazer sentido se não atende às novas gerações de estudantes, principalmente na era digital na qual estamos. Também Dewey (1916), em seu livro Democracia e Educação, já criticava há mais de um século a aprendizagem meramente transmissional como atrasada e ineficaz, sendo que nos dias de hoje não é diferente.

Além disso, o aprender do aluno não se dá de forma uníssona e síncrona entre todos. Natel, Tarcia e Sigulem (2013, p. 143) argumentam que "são diferentes as formas de apreender e aprender os dados de uma dada realidade, uma vez que a cognição está associada ao modo como a pessoa adquire, armazena e usa o conhecimento". Em vista desses argumentos, percebe-se que não tratamos de taxar como inócua a transmissão do conhecimento baseada na escola tradicional, pois o que se posta aqui é a necessidade de maior 


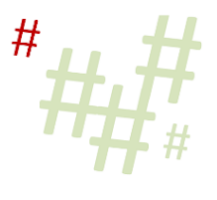

diversidade na prática do ensinar, com vistas a suprir as múltiplas formas pelas quais a informação é apropriada pelo indivíduo e, assim, construir o seu conhecimento. Conhecimento esse que não se dá apenas pela retenção da informação, pois o aluno deve ter papel ativo para dar significado a essa informação, levando-se em conta seus conhecimentos prévios para, a partir da (re)construção do conhecimento, aplicá-lo no contexto real em que vive (VALENTE, 2014).

E corroborando com esse direcionamento da necessidade das múltiplas formas de ensino para os alunos, Bacich, Neto e Trevisani (2015) argumentam que se deve utilizar das tecnologias disponíveis para assegurar que os alunos aprendam, pois se de um lado um aluno aprende melhor com vídeo, um segundo pode ser com leitura, um terceiro ao resolver uma problemática relativa ao conteúdo, e um quarto apenas pelo ouvir. Dessa forma, o aprendizado apresentado deve ser amplo, de modo a combinar todas as formas necessárias e disponíveis. Então, vemos que ao aluno não se deve limitar às formas pelas quais a informação é apresentada, e sim misturar, mesclar e combinar as maneiras com fins de ampliar as possibilidades de apropriação da informação por ele e, dessa maneira, apresentaremos questões pertinentes a essas junções ao tratar de aprendizagem híbrida.

A aprendizagem híbrida surgiu, segundo Godinho e Garcia (2016), por volta do início do século XXI e é oriunda do campo empresarial, no entanto, a metodologia evoluiu e adentrou nas salas de aula através do uso de ferramentas e abordagens distintas. Assim, percebe-se que esse modelo não foi criado com vistas à educação, mas apropriado por ela. Contudo, Moran (2015) salienta que esse termo, contemporaneamente, é mais perceptível no âmbito da educação, muito embora a educação sempre tenha sido híbrida, em maior ou menor grau, pois "sempre combinou vários espaços, tempos, atividades, metodologias, públicos. Esse processo, agora, com a mobilidade e a conectividade, é muito mais perceptível, amplo e profundo: é um ecossistema mais aberto e criativo" (p. 27). Nesse cenário, o ensino torna-se mais rico, através da mistura híbrida podemos criar e planejar variadas formas de implementar estratégias diversificadas para o ensino de determinado conteúdo.

Ao tratarmos de aprendizagem híbrida é interessante conceituá-la sob variadas perspectivas, assim passemos a Barcelos e Batista (2019, p. 61) que a delimitam "como uma modalidade de ensino formal na qual ocorrem atividades presenciais e on-line, de forma integrada e personalizada, com o objetivo de melhorar a construção de conhecimentos sobre o tema em estudo". Sob esse enfoque, temos um ensino tanto presencial quanto virtual, no entanto, um ensino individualizado é destacado. Tal pensamento é corroborado por Grant e Basye (2014) ao enfatizarem que um ensino personalizado pode contribuir para uma maior autonomia e engajamento do aluno e torná-lo, dessa forma, mais ativo e comprometido com seu estudo.

Segundo Hoffmann (2016), o ensino híbrido é um modelo contemporâneo e se utiliza do presencial e virtual mediado por tecnologia, sendo assim, para que haja maior sucesso desse ensino é necessário que a competência para o uso dessa tecnologia seja compartilhada tanto pelos professores como pelos alunos, e também por aqueles que auxiliam o aluno em casa. De certa forma, hoje temos uma geração chamada nativos digitais que são os indivíduos que nasceram no âmbito da era digital (PRENSKY, 2001), ou seja, a partir dos anos 80 e 90 do século passado e que já possuem uma maior facilidade com as tecnologias, o que facilita sua adequação à aprendizagem híbrida.

A aprendizagem híbrida permeia o ensino individualizado em contraponto a um ensino generalista trazido pelo ensino tradicional, uma vez que esta é uma maneira de customizar o ensino e aprendizagem, tornando esse processo individual para cada estudante, rompendo 
assim o modelo tradicional de sala de aula predominante no ensino pelo país (RANGEL; OLIVEIRA; MARCELINO, 2018) (VALENTE, 2018).

A partir do uso das tecnologias, a aprendizagem híbrida permite ao estudante um maior controle sobre o seu próprio tempo e lugar de estudo, muito embora esteja sempre vinculado ao presencial e virtual. Essa relação sempre estará presente para os alunos, pois por vezes terão que realizar alguma atividade relativa à aula virtual em uma localidade física fora de sua residência ou vice-versa (CHRISTENSEN; HORN; STAKER, 2013) (SPINARDI; BOTH, 2018). Esse entrelaçamento entre o presencial e o virtual é bom, uma vez que nas relações sociais advindas dos encontros presenciais a troca de informações se dá de forma mais pessoal e natural, sendo que este tipo de contato, e as riquezas de detalhes que dele se abstraem, não seria possível através apenas do contexto virtual, o qual possui também características próprias de relações que para alguns alunos mais reservados possam abrir novos contatos e diálogos que serão continuados nos momentos presenciais, trazendo assim um ciclo benéfico para todos.

Nesse sentido, o uso da tecnologia digital representa um elemento essencial ao novo modelo contemporâneo do que é o ensino híbrido. Bacich, Neto e Trevisani (2015) corroboram o pensamento sobre o uso do presencial e do virtual, além de destacarem o estudante como elemento ativo e coparticipante do seu aprendizado ao enfatizarem que no ensino híbrido se pressupõe "o uso da tecnologia para o desenvolvimento das atividades dentro e fora da classe, em que o aluno é estimulado a buscar o conhecimento com a mediação do professor e da escola (p. 181). Temos, então, que o ensino híbrido alia tecnologias digitais ao ensino e permite atividades que entrelaçam modalidades presenciais e virtuais, além de trazer o sujeito como ativo na construção de seu conhecimento (CHAVES FILHO, 2006) (RODRIGUES, 2010) (GOUVEIA, 2006) (SPINARDI; BOTH, 2018).

Muito embora o pensamento misto do ensino, Felipe e Orvalho (2004) argumentam que a estratégia da aprendizagem híbrida vai muito além dessa combinação presencial e virtual, pois esta é "muito mais do que uma multiplicação de canais, é uma combinação de métodos de ensino/aprendizagem" (p. 217). Sob a perspectiva de atores que devem estar presentes no contexto de um ensino híbrido, Camillo, Vargas e Medeiros (2018) estabelecem que "para que ocorra [ensino híbrido] é necessário que a tecnologia, o papel do educador, a gestão, a avaliação, bem como a autonomia do educando, a cultura escolar e o espaço estejam em sincronia" (p. 2-3). Ou seja, não se trata da autonomia do aluno em um sentido total, mas sim a busca do conhecimento, muito embora não seja alheio às orientações dadas pelo professor.

Ao analisar os conceitos aqui expostos, percebe-se que basicamente se direcionaram sob três pontos: mescla entre o ensino presencial e virtual; mescla entre a educação tradicional e uma educação mais centrada no aluno; e, por fim, mescla entre currículo e métodos.

No entanto, esses conceitos aplicados à aprendizagem híbrida não são uniformes e nem uníssonos como afirmam Anjos, Silva e Anjos (2019) quando destacam que ainda há dubiedades sobre a temática do ensino híbrido e, que assim sendo, acarretam dissonâncias ou mesmo divergências quando de sua aplicação dentro de um contexto no campo educativo. Muito embora esse direcionamento dos autores é necessário um balizamento de nossa pesquisa para situarmos e conceituarmos o ensino híbrido para melhor orientação do trabalho. Com isso, estabelecemos para nossa pesquisa que ensino híbrido é muito mais do que o mix presencial e online, e para tal nos pautamos em Morin (2015) quando este diz que

Na educação, acontecem vários tipos de mistura, blended ou educação híbrida: de saberes e valores, quando integramos várias áreas de conhecimento (no modelo 
disciplinar ou não); de metodologias, com desafios, atividades, projetos, games, grupais e individuais, colaborativos e personalizados. Também falamos de tecnologias híbridas, que integram as atividades da sala de aula com as digitais, as presenciais com as virtuais. Híbrido também pode ser um currículo mais flexível, que planeje o que é básico e fundamental para todos e que permita, ao mesmo tempo, caminhos personalizados para atender às necessidades de cada aluno. Híbrido também é a articulação de processos de ensino e aprendizagem mais formais com aqueles informais, de educação aberta e em rede. Implica misturar e integrar áreas, profissionais e alunos diferentes, em espaços e tempos distintos. São muitas as questões que impactam o ensino híbrido, o qual não se reduz a metodologias ativas, ao mix de presencial e on-line, de sala de aula e outros espaços, mas que mostra que, por um lado, ensinar e aprender nunca foi tão fascinante, pelas inúmeras oportunidades oferecidas, e, por outro, tão frustrante, pelas dificuldades em conseguir que todos desenvolvam seu potencial e se mobilizem de verdade para evoluir sempre mais. (MORAN, 2015, p. 28-29).

Sob esse argumento conceituamos para nossa pesquisa aprendizagem híbrida como estratégia que se utiliza da integração entre o ensino presencial e o virtual por meio das tecnologias, como também por mesclas de ensino presencial e não presencial, fundamentadas em métodos ativos como também em currículos flexíveis, a partir de ambientes formais, não formais e informais de ensino. Pois, como é destacado por Barcelos e Batista (2019), não basta que o "simples uso de tecnologias on-line caracterize Ensino Híbrido, ou seja, o uso esporádico de um ambiente virtual de aprendizagem, ou de um site ou software não possibilita considerar que a modalidade é híbrida" (p. 63). Dessa forma, a aprendizagem híbrida não se dá apenas pelo uso de recursos digitais, e sim a partir de método planejado, resultando em dividendos significativos à apropriação, interpretação e aplicação da informação pelo aluno, gerando com isso conhecimento, pois de outro modo será uma mera reprodução do sistema tradicional, traduzindo-se apenas como "uma aula enriquecida com tecnologias" (p. 61).

\section{A Legislação hodierna para o uso de tecnologias digitais no ensino}

Ao estarmos conscientes que contemporaneamente a utilização da tecnologia é essencial para a aprendizagem híbrida, temos que nos guiar pelos marcos legais que norteiam o uso de tecnologias digitais e o ensino no Brasil, tendo em vista suas relações com a característica virtual presente na aprendizagem híbrida. Dessa forma, dentre as normativas pertinentes à aprendizagem híbrida hodiernamente no país, destacamos três documentos legais que tratam do ensino mediado por tecnologias, organizados em ordem cronológica:

a) Decreto $\mathrm{n}^{\circ}$ 9.057, de 25 de maio de 2017: Regulamenta o art. 80 da Lei $\mathrm{n}^{\circ}$ 9.394, de 20 de dezembro de 1996, que estabelece as diretrizes e bases da educação nacional;

b) Resolução no 3, de 21 de novembro de 2018: Atualiza as Diretrizes Curriculares Nacionais para o Ensino Médio;

c) Parecer CNE/CP no: 5/2020 (retificado pelo $N^{\text {o: }}$ 9/2020 e homologado dia 09.07.2020 no Diário Oficial da União): Reorganização do Calendário Escolar e da possibilidade de cômputo de atividades não presenciais para fins de cumprimento da carga horária mínima anual, em razão da Pandemia da COVID-19.

Essas normativas não serão objeto de observação em si, mas sob aspectos relativos a contribuições para a implementação da aprendizagem híbrida no país em nível de educação básica. 
Dessa forma, passamos à primeira normativa que é o Decreto $\mathrm{N}^{\circ} 9.057$, de 25 de maio de 2017, que estabeleceu a possibilidade do ensino a distância em toda a educação básica em seu capítulo II, permitindo os sistemas de ensino dos estados e municípios que possam autorizar o funcionamento nesse modelo.

\section{CAPÍTULO II}

\section{DA OFERTA DE CURSOS NA MODALIDADE A DISTÂNCIA NA EDUCAÇÃO BÁSICA}

Art. $8^{\circ}$ Compete às autoridades dos sistemas de ensino estaduais, municipais e distrital, no âmbito da unidade federativa, autorizar os cursos e o funcionamento de instituições de educação na modalidade a distância nos seguintes níveis e modalidades:

I - ensino fundamental, nos termos do $\S 4^{\circ}$ do art. 32 da Lei $n^{\circ} 9.394$, de 20 de dezembro de 1996 ;

II - ensino médio, nos termos do $§ 11$ do art. 36 da Lei no 9.394, de 1996. (BRASIL, 2017, p. 1).

No entanto, faz a ressalva de que sua implementação está vinculada a situações excepcionais de emergência.

Art. $9^{\circ}$ A oferta de ensino fundamental na modalidade a distância em situações emergenciais, previstas no $\S 4^{\circ}$ do art. 32 da Lei $n^{\circ}$ 9.394, de 1996, se refere a pessoas que:

I - estejam impedidas, por motivo de saúde, de acompanhar o ensino presencial;

II - se encontrem no exterior, por qualquer motivo;

III - vivam em localidades que não possuam rede regular de atendimento escolar presencial;

IV - sejam transferidas compulsoriamente para regiões de difícil acesso, incluídas as missões localizadas em regiões de fronteira; ou

V - estejam em situação de privação de liberdade. (BRASIL, 2017, p. 1).

A permissão da adoção do ensino a distância no sistema de ensino público do país foi relevante para a aprendizagem híbrida, tendo em vista que tornou legal sua implementação na educação básica e atribuiu aos estados e municípios essa autorização, descentralizando e facilitando, assim, a sua prática.

A segunda normativa é a Resolução n ${ }^{\circ}$, de 21 de novembro de 2018, que atualizou as Diretrizes Curriculares Nacionais para o Ensino Médio. Nessa Resolução foram estabelecidos percentuais máximos para a educação a distância ao ensino médio regular e ensino de jovens e adultos - EJA.

\section{CAPÍTULO II}

\section{FORMAS DE OFERTA E ORGANIZAÇÃO}

Art. 17. O ensino médio, etapa final da educação básica, concebida como conjunto orgânico, sequencial e articulado, deve assegurar sua função formativa para todos os 
estudantes, sejam adolescentes, jovens ou adultos, mediante diferentes formas de oferta e organização.

$\S 5^{\circ} \mathrm{Na}$ modalidade de educação de jovens e adultos é possível oferecer até $80 \%$ (oitenta por cento) de sua carga horária a distância, tanto na formação geral básica quanto nos itinerários formativos do currículo, desde que haja suporte tecnológico digital ou não - e pedagógico apropriado.

$\S 15$. As atividades realizadas a distância podem contemplar até $20 \%$ (vinte por cento) da carga horária total, podendo incidir tanto na formação geral básica quanto, preferencialmente, nos itinerários formativos do currículo, desde que haja suporte tecnológico - digital ou não - e pedagógico apropriado, necessariamente com acompanhamento/coordenação de docente da unidade escolar onde o estudante está matriculado, podendo a critério dos sistemas de ensino expandir para até 30\% (trinta por cento) no ensino médio noturno. (BRASIL, 2018, p. 1)

Em suma, temos que para o ensino médio diurno e noturno abriu-se a possibilidade de atividade a distância em até $20 \%$ e $30 \%$ da carga horária respectivamente, sendo prioritariamente aplicada aos itinerários formativos (áreas optativas), sempre sob a orientação de um professor. E para a Educação de Jovens e Adultos (EJA) a possibilidade se estendeu até $80 \%$ da carga horária.

No que se refere à aprendizagem híbrida, a normativa trouxe benefícios à sua prática, tendo em vista que estabeleceu percentuais de ensino a distância que podem ser utilizados pelos sistemas de ensino como forma de diversificar os modelos de ensino postos hodiernamente, com fins a ser uma complementaridade ao ensino presencial.

A terceira normativa é o Parecer CNE/CP No: 5/2020 (retificado pelo No: 9/2020 e homologado dia 09.07.2020 no Diário Oficial da União) que dispõe sobre a reorganização do calendário escolar e a possibilidade de cômputo de atividades não presenciais para fins de cumprimento da carga horária mínima anual, em razão da Pandemia da COVID-19. A normativa foi inserida para possibilitar o ensino remoto a todas as redes do país, de forma temporária. No entanto, mesmo sendo uma normativa pontual por conta da situação pandêmica, é de grande importância pelos resultados que podem advir da abrupta adaptação na qual foi imposta toda a sociedade e, sem dúvida, impactou consideravelmente na educação atual, podendo seus reflexos se estenderem ou se estabelecerem no contexto pós-pandêmico.

\section{I - RELATÓRIO}

\section{[...] 2. Análise}

A situação que se apresenta em decorrência da pandemia da COVID-19 não encontra precedentes na história mundial do pós-guerra. Segundo a Organização das Nações Unidas para a Educação, a Ciência e a Cultura (UNESCO), milhões de estudantes estão sem aulas com o fechamento total ou parcial de escolas e universidades em mais de 150 países devido à pandemia do coronavírus. No Brasil, as aulas presenciais estão suspensas em todo o território nacional e essa situação, além de imprevisível, deverá seguir ritmos diferenciados nos diferentes Estados e Municípios, a depender da extensão e intensidade da contaminação pela COVID-19. (MEC, 2020, p. 2)

\section{[...] 2.4 Da reorganização do calendário escolar}

Por atividades não presenciais entende-se, neste parecer, aquelas a serem realizadas pela instituição de ensino com os estudantes quando não for possível a presença 
física destes no ambiente escolar. A realização de atividades pedagógicas não presenciais visa, em primeiro lugar, que se evite retrocesso de aprendizagem por parte dos estudantes e a perda do vínculo com a escola, o que pode levar à evasão e abandono. (idem, p. 6)

Em suma, por meio da normativa, o MEC suspendeu as aulas em todo o país e abriu a possibilidade para atividades não presenciais, estabelecendo a reorganização do calendário escolar, reposição de carga horária e de dias letivos, dentre outros aspectos concernentes à gestão e avaliações dos alunos pelas instituições de ensino.

No que se refere à aprendizagem híbrida, a normativa trouxe benefícios à sua prática, tendo em vista que ao suspender as aulas por conta da pandemia, autorizou e orientou as formas de se realizar a atividade não presencial para todas as instituições de ensino do Brasil. As instituições tiveram que se adequar repentinamente a esse novo modelo remoto no qual, em razão do decurso para seu fim, tende a deixar fundamentos para que no pós-pandemia o ensino mediado por tecnologia seja implementado complementarmente ao ensino presencial. Tal cenário aponta para uma abreviação da implementação do ensino híbrido no Brasil que já tendia a ser posto em prática por conta dos avanços das tecnologias, entretanto em virtude da pandemia da COVID-19 pode ter sido reduzido em algumas décadas.

Cabe ressaltar que após a pandemia possivelmente haverá um maior hibridismo da educação presencial com o EAD, pois cada vez mais os professores estarão preparados para o distanciamento, tendo a possibilidade factível de novas doenças coletivas futuras. Essa probabilidade nunca mais será descartada. (PASINI; CARVALHO; ALMEIDA, 2020, p. 8)

Essas três normativas trouxeram uma maior possibilidade de uso de atividades por meio de tecnologias digitais na educação básica pública no Brasil e, por conseguinte, à prática de aprendizagem híbrida. Dessa forma, nota-se uma tendência recente de combinação entre ensino presencial e virtual no país que, aos poucos, ia se delineando e construindo assim sua base de aplicação, pois com o avanço tecnológico e as influências que estas impõem a toda a sociedade é inevitável que a educação passe incólume a essas mudanças, como destacam Abrantes e Souza (2016), Hoffmann (2016) e Christensen, Horn e Staker (2013).

A geração digital está moldando a educação, pois a mesma vive, comunica-se e aprende de um modo diferente, para o qual habilidades, atitudes e comportamentos novos tornam-se espontâneos. O novo panorama da sociedade da informação baseia-se nas necessidades de aprendizagem e teorias que descrevem os princípios e processos de aprendizagem, que reflitam sobre o ambiente social vigente. (ABRANTES; SOUSA, 2016, p. 198-199)

O Ensino Híbrido ainda é pouco conhecido no Brasil, também denominado blended learning, combinação do aprendizado nos ambientes virtual e presencial, vem ganhando força nos últimos anos. A modalidade de ensino à distância está cada vez mais presente e formando um grande número de profissionais que estudam conforme as suas possibilidades. Vem se consolidando como tendência para o futuro. (HOFFMANN, 2016, p. 18)

Prevemos que as escolas híbridas, que combinam as escolas existentes com novos modelos de sala de aula, serão o modelo dominante de educação do futuro nos Estados Unidos. Dentro das escolas de Ensino Fundamental, no entanto, os modelos disruptivos de ensino híbrido substituirão substancialmente as salas de aula tradicionais no longo prazo. (CHRISTENSEN; HORN; STAKER, 2013, p. 4) 
Assim, tal qual a geração digital se comunica por ambiente virtual, o movimento da educação tende a seguir esse caminho e, dessa forma, a influência das tecnologias e o seu uso prático se coloca como opção válida a ser apropriada no ensino contemporâneo, apontando para o futuro do ensino no Brasil e no mundo. É importante destacar que essas referências partem - predominantemente - de anos anteriores à pandemia da COVID-19, e nela já se vislumbrava a inclinação do ensino mediado por tecnologias na educação hodierna e, com isso, a paulatina consolidação da aprendizagem híbrida.

Este é o momento crucial para que as instituições de ensino repensem os seus processos pedagógicos, tendo em vista que nesse cenário no qual estamos não houve um tempo de preparo para o que vivenciamos, então devemos sim reinventar as formas de se fazer educação. Vemos que por vezes há resistência quanto ao uso de tecnologia, principalmente por parte daqueles profissionais mais antigos, mas isso é questão apenas de hábito e preparo para tal. Muito embora saibamos que nada poderá substituir o professor e o aluno em sala de aula e suas trocas de informações, estamos em um tempo onde a exceção parece ser a regra e, além disso, a tecnologia digital indubitavelmente veio para ficar. Ora posto, a aprendizagem híbrida não parece ser um cenário que tende a ser cessado com o passar do estado pandêmico, e sim estar cada vez mais presente nas instituições escolares através de atividades complementares, no contraturno ou mesmo durante o horário das aulas regulares dos alunos.

A partir do exposto, urge a necessidade de legislações que versem sobre essa temática. E nota-se que já há uma orientação para tal nos dias atuais no Brasil, apontamos para isso as três legislações destacadas que foram normatizadas a menos de 5 anos, o que demonstra um forte direcionamento para os modelos de ensino baseados na aprendizagem híbrida. Ademais, não podemos esquecer que o uso pelo uso de tecnologias digitais não é prudente, assim, deve-se estabelecer discussões críticas entre as instituições, as redes de ensino e os poderes instituídos, sejam eles municipais, estaduais ou federais, sobre o uso coerente e viável das tecnologias levando-se em conta questões pertinentes ao seu acesso pelos indivíduos, principalmente àqueles com menor poder aquisitivo, como também à forma como as tecnologias digitais serão dispostas ou organizadas em complementaridade ao ensino presencial público no país. É apropriado destacar que para os pontos realçados acima, a legislação é ponto crucial e, assim, deve e será utilizada à normatização e à implementação das ações delineadas pelos entes e atores educacionais, a partir da observação de cenário específico.

\section{Considerações finais}

No sentido de trazer ao leitor as considerações finais relativas à pesquisa realizada, retomamos o objetivo da investigação que se propôs a identificar as legislações que fundamentam o uso de tecnologias digitais para o ensino no Brasil hodiernamente, com fins de apresentar os marcos legais que permitem a aprendizagem híbrida através da utilização das tecnologias digitais no país. Logo, por meio da pesquisa, identificamos e destacamos três legislações hodiernas que estabelecem orientações para o uso de tecnologias digitais, as quais são: Decreto $n^{\circ}$ 9.057, de 25 de maio de 2017: Regulamenta o art. 80 da Lei n ${ }^{\circ} 9.394$, de 20 de dezembro de 1996, que estabelece as diretrizes e bases da educação nacional; Resolução nº 3 , de 21 de novembro de 2018: Atualiza as Diretrizes Curriculares Nacionais para o Ensino Médio; e por fim, o Parecer CNE/CP N: 5/2020 (retificado pelo $\mathrm{N}^{\circ}$ : 9/2020 e homologado dia 09.07.2020 no Diário Oficial da União): Reorganização do Calendário Escolar e da 
possibilidade de cômputo de atividades não presenciais para fins de cumprimento da carga horária mínima anual, em razão da Pandemia da COVID-19.

Ademais, como observações complementares advindas deste estudo, destacamos que a aprendizagem híbrida é uma modalidade mista de ensino, podendo perfazer sob vários enfoques relacionais que entrelaçam o presencial ao virtual. Ressaltamos que sua utilização pode trazer estratégias pedagógicas oportunas ao se utilizar do ensino presencial e virtual da melhor forma, na qual estes podem ser dispostos de acordo com o contexto específico que será implementado. Além disso, a aprendizagem híbrida traz uma possibilidade para que o aluno possa aprender a seu tempo, pois a mobilidade presente com o uso de tecnologias digitais permite tal disposição do conteúdo. O professor também pode se valer da tecnologia para aplicar conteúdos mais específicos para determinados alunos ou grupos. No que se refere às legislações, temos que, nos últimos anos, com o advento da internet e o avanço tecnológico, esses marcos legais tiveram que se adequarem aos novos tempos e, por conta disso, vemos que a tecnologia digital aplicada ao ensino está mais presente nessas normativas, pois é indubitável que a evolução tecnológica influencie nessas leis. Dessarte, em períodos de tempo cada vez menores, haverá a necessidade de novas adequações da legislação frente aos avanços digitais que se postam em nosso tempo.

Logo, entendemos que nossos resultados corroboram autores que salientam que a aprendizagem híbrida é uma tendência hodierna devido ao avanço das tecnologias digitais sobre todos os campos da atividade humana e destacamos, assim, a educação de um modo geral, especificamente o ensino. Ademais, essa tendência reflete invariavelmente a necessidade de criação/reformulação de legislações que observem todo o contexto social, econômico, histórico, político e educacional que circunda a temática, com vistas a implementar orientações que tenham como fins um ensino público de qualidade em nosso país.

Importante destacarmos que, embora tenhamos alcançado os objetivos propostos para esse recorte investigativo, há dimensões da constituição dessas legislações para além das perspectivas aqui discutidas, pois existe todo um cenário que não envolve apenas a legislação escrita em si, e sim os próprios interesses e atores que se propuseram ou mesmo participaram ativamente sobre cada uma delas com fins de favorecer determinado lado ou a si próprio, dentre outras vertentes investigatórias que podem irradiar desse novo olhar sobre o objeto que é a legislação educacional. Isso é um caminho ainda a ser trilhado.

\section{Referências}

ABRANTES, M. G. L. D.; SOUSA, R. P. D. Formação Continuada e Conectivismo: um Estudo de Caso Referente às Transformações da Prática Pedagógica no Discurso do Professor. In: SOUSA, R. P. D. et al. Teorias e práticas em tecnologias educacionais. Campina Grande-PB: UFCG, 2016. p. 227. Disponível em: https://static.scielo.org/scielobooks/fp86k/pdf/sousa-9788578793265.pdf. Acesso em: 27 out. 2020.

ANJOS, R. A. V. D.; SILVA, L. M. D.; ANJOS, A. M. D. Ensino Híbrido: Organização e Sistematização de Conceitos Com Base em Revisão Sistemática da Literatura. EmRede: Revista de Educação a Distância, Porto Alegre-RS, v. 6, n. 2, p. 203-220, out. 2019. Disponível em: https://www.aunirede.org.br/revista/index.php/emrede/article/view/467. Acesso em: 26 out. 2020. 
BACICH, L.; NETO, A. T.; TREVISANI, F. D. M. Ensino híbrido: personalização e tecnologia na educação. [S.1.]: Penso Editora, 2015.

BARCELOS, G. T.; BATISTA, S. C. F. Ensino Híbrido: aspectos teóricos e análise de duas experiências pedagógicas com Sala de Aula Invertida. Renote, Porto Alegre, v. 17, n. 02, p. 60-75, ago. 2019. Disponível em:

https://www.seer.ufrgs.br/renote/article/viewFile/96587/54187. Acesso em: 25 out. 2020.

BRASIL. MEC. Decreto $\mathbf{n}^{\mathbf{0}} \mathbf{9 . 0 5 7}$, de 25 de maio de 2017. Regulamenta o art. 80 da Lei $\mathbf{n}^{\mathbf{o}}$ 9.394, de 20 de dezembro de 1996, que estabelece as diretrizes e bases da educação nacional, 2017. Disponível em:

http://www.planalto.gov.br/ccivil_03/_ato2015-2018/2017/decreto/d9057.htm. Acesso em: 26 out. 2020.

BRASIL. MEC. Resolução no 3, de 21 de novembro de 2018: Atualiza as Diretrizes Curriculares Nacionais para o Ensino Médio., 2018. Disponível em:

http://novoensinomedio.mec.gov.br/resources/downloads/pdf/dcnem.pdf. Acesso em: 26 out. 2020.

CAMILLO, C. M.; VARGAS, M. E. G.; MEDEIROS, L. Ensino Híbrido: a Sala de Aula Invertida Como Possibilidade de Ensino e Aprendizagem. In: ELPED E ENCONTRO DE LICENCIATURAS E DO PIBID DO SUDOESTE GOIANO, 3. e 4., 2018, Rio Verde. Anais [...]. Rio Verde, 2018. p. 1-10.

CHAVES FILHO, H. Educação a distância em organizações públicas: mesa redonda de pesquisa-ação. Brasília: Enap, 2006. Disponível em:

https://repositorio.enap.gov.br/bitstream/1/376/1/Livro_EAD.pdf. Acesso em: 26 out. 2020.

CHRISTENSEN, C.; HORN, M.; STAKER, H. Ensino Híbrido: uma Inovação Disruptiva? Uma introdução à teoria dos híbridos, traduzido por Fundação Lemann e Instituto Península. [S.1.]: [s.n.], 2013. Disponível em:

http://porvir.org/wpcontent/uploads/2014/08/PT_Is-K-12-blended-learning-disruptive-Final.p df. Acesso em: 26 out. 2020.

DEWEY, J. Democracy and Education. New York: The Free Press, 1916.

DORIGONI, G. M. L.; SILVA, J. C. D. Mídia e Educação: o uso das novas tecnologias no espaço escolar. Portal Dia a Dia Educação, Curitiba, v. 2, p. 1-18, 2007. Disponível em: http://www.diaadiaeducacao.pr.gov.br/portals/pde/arquivos/1170-2.pdf. Acesso em: 26 out. 2020.

FELIPE, A. J. M.; ORVALHO, J. G. Blended-learning e a aprendizagem colaborativa no ensino superior. In: CONGRESSO IBEROAMERICANO DE INFORMÁTICA EDUCATIVA, 7., 2004, Porto Alegre. Anais [...]. Porto Alegre, 2004. p. 216-225.

GIL, A. C. Como elaborar projetos de pesquisa. 4. ed. São Paulo: Atlas, 2002.

GODINHO, V. T.; GARCIA, C. A. A. Caminhos híbridos da educação-delimitando. In: SIMPÓSIO INTERNACIONAL DE EDUCAÇÃO A DISTÂNCIA, ENCONTRO DE 
PESQUISADORES EM EDUCAÇÃO A DISTÂNCIA, 2016, São Carlos. Anais [...]. São Carlos: UFSCAR, 2016. p. 1-11.

GOUVEIA, L. B. A necessidade de capacitar conhecimento para o território. T-MEDIA e Ciência, A revista da Ciência, Tecnologia e Inovação em Portugal, Cartaxo, v. 19, p. 1-4, out. 2006. Disponível em:

https://www.researchgate.net/profile/Luis_Borges_Gouveia/publication/228327926_A_necess idade_de_capacitar_conhecimento_para_o_territorio/links/573cf62108ae9ace840feae $9 / \mathrm{A}-\mathrm{nec}$ essidade-de-capacitar-conhecimento-para-o-territorio.pdf. Acesso em: 26 out. 2020.

GRANT, P.; BASYE, D. Personalized learning: a guide for engaging students with technology. Washington: International Society for Technology in Education, 2014. Disponível em:

https://www.intel.com/content/dam/www/public/us/en/documents/education/k12-personalized -learning-guidebook.pdf. Acesso em: 25 out. 2020.

HOFFMANN, E. H. O ensino híbrido no ensino fundamental: possibilidades e desafios. 2016. Trabalho de Conclusão de Curso (Especialização) - Universidade Federal de Santa Catarina, Centro de Ciências da Educação. Florianópolis-SC, 2016.

MEC. Conselho Nacional de Educação. Parecer CNE/CP Nº: 5/2020, 2020. Disponível em: http://www.abrafi.org.br/js/ckeditor/foto_internas/pcp005_20.pdf. Acesso em: 16 maio 2020.

MORAN, J. Educação híbrida: um conceito-chave para a educação, hoje. In: BACICH, L.; TANZI NETO, A.; TREVISANI, F. D. M. Ensino Híbrido: personalização e tecnologia na educação. Porto Alegre: Penso, 2015. p. 27-53. Disponível em:

https://docplayer.com.br/38155848-Educacao-hibrida-um-conceito-chave-para-a-educacao-ho je-muitas-misturas.html. Acesso em: 26 out. 2020.

NATEL, M. C.; TARCIA, R. M. L. D.; SIGULEM, D. A aprendizagem humana: cada pessoa com seu estilo. Rev. psicopedag., São Paulo, v. 30, n. 92, p. 142-148, 2013. Disponível em: http://pepsic.bvsalud.org/scielo.php?script=sci_arttext\&pid=S0103-84862013000200008\&lng $=$ pt\&nrm=iso. Acesso em: 25 out. 2020 .

OLIVEIRA, E. G1. Estados adotam plataformas online e aulas na TV aberta para levar conteúdo a estudantes em meio à pandemia de coronavírus, 2020. Disponível em: https://g1.globo.com/educacao/noticia/2020/04/09/estados-adotam-plataformas-online-e-aulas -na-tv-aberta-para-levar-conteudo-a-estudantes-em-meio-a-pandemia-de-coronavirus.ghtml. Acesso em: 22 maio 2020.

PASINI, C. G. D.; CARVALHO, É. D.; ALMEIDA, L. H. C. A Educação Híbrida em Tempos de Pandemia: Algumas Considerações. In: Observatório Socioeconômico da COVID-19. Santa Maria: UFMS, 2020. p. 1-9.

PRENSKY, M. Digital Natives Digital Immigrants. In: PRENSKY, M. On the Horizon. [S.1.]: NCB University Press, v. 9, 2001. p. 1-6. Disponível em: https://www.marcprensky.com/writing/Prensky\%20-\%20Digital\%20Natives,\%20Digital\%20I mmigrants\%20-\%20Part1.pdf. Acesso em: 27 out. 2020. 
RANGEL, F. C. D. S.; OLIVEIRA, L. G. D.; MARCELINO, V. D. S. M-learning Associado ao Método Cooperativo de Aprendizagem Jigsaw. CIET:EnPED. [S.1.], p. 1-12. 2018.

RODRIGUES, L. A. Uma Nova Proposta Para o Conceito de Blended Learning. Interfaces da Educ., Paranaíba-MS, v. 1, n. 3, p. 5-22, 2010. Disponível em:

http://docplayer.com.br/1071699-Interfaces-da-educacao-5.html. Acesso em: 26 out. 2020.

SANTAELLA, L. Desafios da Ubiquidade para educação. Ensino Superior Unicamp, Campinas, v. 9, p. 19-28, abr./jun. 2013. Disponível em:

https://www.revistaensinosuperior.gr.unicamp.br/artigos/desafios-daubiquidade-para-a-educac ao. Acesso em: 2 nov. 2020.

SPINARDI, J. D.; BOTH, I. J. Blended learning: o ensino híbrido e a avaliação da aprendizagem no ensino superior. Boletim Técnico do Senac, v. 44, n. 1, p. 1-12, mar. 2018. Disponível em: https://www.bts.senac.br/bts/article/view/648/562. Acesso em: 26 out. 2020.

TAPSCOTT, D.; WILLIAMS, A. D. Innovating the 21st-Century University: It's Time!

Educause Review, p. 17-29, jan./fev. 2010. Disponível em:

https:/er.educause.edu/articles/2010/2/innovating-the-21stcentury-university-its-time. Acesso em: 25 out. 2020 .

VALENTE, J. A. Blended learning e as mudanças no ensino superior: a proposta da sala de aula invertida. Educ. rev., Curitiba, v. especial 4, p. 79-97, 2014. Disponível em:

http://www.scielo.br/scielo.php?script=sci_arttext\&pid=S0104-40602014000800079\&lng=en $\&$ nrm=iso. Acesso em: 25 out. 2020.

VALENTE, J. A. A sala de aula invertida e a possibilidade do ensino personalizado: uma experiência com a graduação em midialogia. In: BACICH, L.; MORAN, J. Metodologias ativas para uma educação inovadora: uma abordagem teórico-prática. Porto Alegre: Penso, 2018. p. 26-44. Disponível em:

https://statics-submarino.b2w.io/sherlock/books/firstChapter/132759983.pdf. Acesso em: 26 out. 2020 .

Recebido em março de 2021.

Aprovado em maio de 2021. 